\title{
Establishment of animal model for the analysis of cancer cell metastasis during radiotherapy
}

\author{
Jong Kuk Park ${ }^{1 \dagger}$, Su Jin Jang ${ }^{2 \dagger}$, Sung Wook Kang ${ }^{1}$, Sunhoo Park ${ }^{3}$, Sang-Gu Hwang ${ }^{1}$, Wun-Jae Kim${ }^{4}$,
} Joo Hyun Kang ${ }^{2^{*}}$ and Hong-Duck Um ${ }^{1^{*}}$

\begin{abstract}
Background: $\lceil$-lonizing radiation (IR) therapy is one of major therapeutic tools in cancer treatment. Nevertheless, $\gamma-\mathrm{IR}$ therapy failed due to occurrence of metastasis, which constitutes a significant obstacle in cancer treatment. The main aim of this investigation was to construct animal model which present metastasis during radiotherapy in a mouse system in vivo and establishes the molecular mechanisms involved.
\end{abstract}

Materials and methods: The C6L transfectant cell line expressing firefly luciferase (fLuc) was treated with $\gamma-\mathrm{IR}$, followed by immunoblotting, zymography and invasion assay in vitro. We additionally employed the C6L transfectant cell line to construct xenografts in nude mice, which were irradiated with $\gamma-$ IR. Irradiated xenograft-containing mice were analyzed via survival curves, measurement of tumor size, and bioluminescence imaging in vivo and ex vivo. Metastatic lesions in organs of mice were further assessed using RT-PCR, H \& E staining and immunohistochemistry.

Results: $\gamma-\mathrm{IR}$ treatment of C6L cells induced epithelial-mesenchymal transition (EMT) and increased cell invasion. In irradiated xenograft-containing mice, tumor sizes were decreased dramatically and survival rates extended. Almost all non-irradiated xenograft-containing control mice had died within 4 weeks. However, we also observed luminescence signals in about $22.5 \%$ of $\gamma$-IR-treated mice. Intestines or lungs of mice displaying luminescence signals contained several lesions, which expressed the fluc gene and presented histological features of cancer tissues as well as expression of EMT markers.

Conclusions: These findings collectively indicate that occurrences of metastases during $Y-I R$ treatment accompanied induction of EMT markers, including increased MMP activity. Establishment of a murine metastasis model during $\gamma-\mathrm{IR}$ treatment should aid in drug development against cancer metastasis and increase our understanding of the mechanisms underlying the metastatic process.

Keywords: Y-lonizing Radiation, Cancer, Metastasis, Epithelial-mesenchymal transition, Bioluminescence imaging, Animal model

\section{Background}

Metastasis is one of the distinct characteristics of cancer and presents a major obstacle to cancer treatment. An estimated $50 \%$ of all cancer patients develop metastasis, which is an important limiting factor in establishing a cure, and elucidation of the mechanisms underlying

\footnotetext{
* Correspondence: kang2325@kirams.re.kr; hdum@kcch.re.kr

${ }^{\dagger}$ Equal contributors

${ }^{2}$ Molecular Imaging Research Center, Korea Institute of Radiological and Medical Sciences, 215-4, Gongneung-Dong, Nowon-Gu, Seoul 139-706, Republic of Korea

'Division of Radiation Cancer Biology, Korea Institute of Radiological and Medical Sciences, 215-4, Gongneung-Dong, Nowon-Gu, Seoul 139-706,

Republic of Korea

Full list of author information is available at the end of the article
}

metastasis is thus important to overcome failure of treatment [1]. Induction of metastasis is critically dependent on the capability of cancer cells to mobilize from the original site. Cancer cells acquiring motility access the vasculature of the lymphatic system via invasion, and attach and proliferate to distant sites with a favorable microenvironment [1-3]. Metastasis is accomplished when proliferating cancer cells in secondary sites form another cell mass that may display different characteristics, in particular, drug or radioresistance, from the original cancer, as a consequence of encountering various microenvironmental and stress factors distinct from the primary site [4-6]. Therefore, migrating cancer

\section{Biomed Central}

(c) 2012 Park et al.; licensee BioMed Central Ltd. This is an Open Access article distributed under the terms of the Creative Commons Attribution License (http://creativecommons.org/licenses/by/2.0), which permits unrestricted use, distribution, and reproduction in any medium, provided the original work is properly cited. 
cells in metastases could be resistant against cell death, and the resistance might depend on activation of the phosphatidylinositol 3-kinase (PI3Kinase) signaling pathway. Activation of the PI3Kinase pathway in metastatic cancer cells due to the highly glycolytic state of the cells $[7,8]$ and aerobic glycolysis could also induce drug resistance in cancer cells $[9,10]$. Resistance against anoikis induced upon cell detachment from the extracellular matrix (ECM), might also be involved in survival of migrating cancer cells $[11,12]$. A few reports have suggested that induction of resistance against anoikis is also derived from activation of the PI3Kinase signaling and extracellular signaling-receptor kinase (ERK) via various proteins involving $\operatorname{TrkB}$, its ligand brain-derived neurotrophic factor (BDNF), and hepatocyte growth factor (HGF) $[13,14]$. PI3Kinase and ERK may also participate in cancer cell migration and invasion by activating various ECM-degrading enzymes, such as the matrix metalloproteinase (MMP) family proteins [15-17]. MMP proteins represent one of the major markers of epithelial-mesenchymal transition (EMT) as well as metastasis [18]. Recent studies have shown that EMT is a fundamental cellular mechanism, promoting cell migration and loss of cell polarity during organ formation and differentiation. Development of gastrulation, neural systems and various internal organs, such as pancreas and liver, are required from induction of EMT $[19,20]$. In cancer, EMT plays various roles in the maintenance of cancer stemness and induction of metastasis, and is inducible by different growth factors, hormones, and intracellular molecules. Several regulators, such as Snail, Twist1 and SIP1, have been shown to mediate EMT and metastasis under signaling of hypoxia/HIF-1, Wnt, Notch, and TGF- $\beta$. Environmental factors, including nicotine, ultraviolet light (UV) and $\gamma$-IR, also promote EMT [20-22]. Induction of EMT appears to be related to resistance against chemotherapy reagents, such as tamoxifen and gemcitabine, as well as radiotherapy [23-25]. Furthermore, EMT stimulates acquisition of elongated cancer cell survival during movement from the primary cancer to distal metastasis site [26].

Around $50 \%$ of all solid cancer patients receive radiation therapy, one of the major current treatment methods. However, recent reports have demonstrated that $\gamma$-IR induces an increase in invasiveness of several cancer cell types, including glioma, hepatocellular carcinoma, and lung cancer cells $[22,27,28]$. This increase in invasiveness is accomplished via enhanced activity and expression of MMP family proteins promoted by various intracellular pro-survival signaling pathways, such as NF-kB and PI3-kinase/AKT. These proteins are known cell survival factors that endow resistance against various stress conditions [29-32].

In the present study, we attempted to establish whether $\gamma$-IR-induced invasion and metastasis are stimulated in our in vitro C6L cell line and in vivo systems, and further identify the associated changes in signal pathways or mice physiology. We constructed an animal model system with a view to clarifying the intracellular molecular events underlying the promotion of metastasis after $\gamma$-IR treatment for primary cancer and developing effective antimetastatic reagents. Our results demonstrate that $\gamma$-IR treatment of cancer cell lines and mice xenografts triggers invasion and metastasis. In particular, $\gamma$-IR-treated cancer cells or mouse xenografts and metastatic lesions in mice bearing $\gamma$-IR-treated xenografts also display typical EMT marker expression patterns, such as increased vimentin or MMP-2 expression, decreased E-cadherin, and enhanced activity of MMP-2. Our results collectively suggest that $\gamma$ IR-induced invasion or metastasis results from induction of EMT, and inhibition of EMT may thus be a means to enhance the effectiveness of radiation therapy.

\section{Materials and methods}

Cell culture and irradiation of $\gamma$-IR

Rat glioma cell C6 cells were obtained from American Type Culture Collection (Rockville, MD), and grown in DMEM (Invitrogen, Grand Island, NY) supplemented with $10 \%$ fetal bovine serum (Invitrogen) in a humidified $5 \% \mathrm{CO}_{2}$ incubator at $37^{\circ} \mathrm{C}$. We employed $\mathrm{C} 6$ to construct $\mathrm{C} 6 \mathrm{~L}$ transfectant cells containing the firefly luciferase (fLuc) gene in lentiviral vectors and selected with blastidin treatment $(5 \mathrm{mg} / \mathrm{mL})$. Irradiation with various doses of $\gamma$-IR was performed with a $\gamma$-IR irradiator using ${ }^{137} \mathrm{Cs}$ as a source of $\gamma$-rays (Atomic Energy of Canada, Ltd., Mississauga, ON).

\section{PCR analysis}

Total RNA was isolated from metastatic lesions, and used as a template to produce cDNA using SuperScript III First-Strand Synthesis for RT-PCR (Invitrogen, CA). Synthesized cDNA was amplified using Taq DNA polymerase (iNtRON, Seoul) with the following primers for fLuc: forward, 5'- CGC CTT GAT TGA CAA GGA TGG, and reverse, 5'- GGC CTT TAT GAG GAT CTC TCT. The forward primer used for glyceraldehyde-3phosphate dehydrogenase (GADPH) was 5'- GGT GAA GGT CGG TGT GAA CG and the reverse primer was 5'- CTC GCT CCT GGA AGA TGG TG.

\section{Invasion analysis}

C6L cells were seeded in a $35 \mathrm{~mm}$ cell culture dish and irradiated with $1,3,5$, or 7 Gy of $\gamma$-IR. Transwell systems containing a $0.8 \mu \mathrm{m}$ pore (Corning, NY) were coated with Matrigel (1 mg/mL, Invitrogen), and preirradiated cells $\left(2 \times 10^{4}\right)$ were washed with serum-free media twice after $18 \mathrm{~h}$ of irradiation. Cells were added to the upper chamber and serum-free medium containing $0.1 \%$ BSA added to the lower chamber of each 
transwell, and incubated for $18 \mathrm{~h}$ with $5 \% \mathrm{CO}_{2}$ at $37^{\circ} \mathrm{C}$. Cell staining was performed with deep quick solution (Merck, Whitehouse Station, NJ), according to the manufacturer's protocol. Photographs of microscopic images of stained cells were taken under a microscope and counted, and then statistical analyses were performed.

\section{Immunoblot analysis}

C6L cells were seeded in a $60 \mathrm{~mm}$ cell culture dish and irradiated with 3 Gy of $\gamma$-IR. Irradiated cells were trypsinized and washed with $1 \times$ ice-cold PBS. RIPA buffer [50 mmol/L Tris, pH.8.0, $150 \mathrm{mmol} / \mathrm{L} \mathrm{NaCl}, 1 \% \mathrm{NP}-40$, $0.5 \%$ deoxycholic acid, and $0.1 \%$ sodium dodecyl sulfate (SDS)] containing protease and phosphatase inhibitor cocktail (Sigma) was used to dissolve harvested cell pellets for acquiring whole-cell protein lysates. Cell lysates were separated by $12 \%$ SDS-polyacrylamide gel electrophoresis (PAGE) and transferred to nitrocellulose membranes (Invitrogen Co., Carlsbad, CA). Protein-transferred membranes were incubated with primary antibodies against Ecadherin, MMP-2 (Santa Cruz Biotechnology, Santa Cruz, CA) or Vimentin (Dako, Glostrup, Denmark). Primary antibody-attached membranes were washed with PBSTween 20 (PBS-T) and incubated with the appropriate secondary antibody. A chemiluminescence kit (Thermo scientific, Rockford, IL) was used to detect target proteins on the nitrocellulose membrane.

\section{Gelatin zymography}

C6L cells were irradiated with $3 \mathrm{~Gy}$, and the media of irradiated cells replaced with serum-free medium. Cells were incubated for $24 \mathrm{~h}$ in serum-free medium under a humidified atmosphere with $5 \% \mathrm{CO}_{2}$ at $37^{\circ} \mathrm{C}$, collected and loaded on to a $0.1 \%$ gelatin SDS-PAGE gel (10\%). After separation of proteins, gel renaturation was performed with $2.5 \%$ Triton X-100 buffer for $1 \mathrm{~h}$, and the gelatin gel incubated with developing solution $(50 \mathrm{mM}$ Tris pH 7.5, $20 \mathrm{mM} \mathrm{NaCl}, 10 \mathrm{mM} \mathrm{CaCl}_{2}, 1 \mu \mathrm{M} \mathrm{ZnCl}$, $0.1 \% \mathrm{NaN}_{3}$ ) for $24 \mathrm{~h}$ at $37^{\circ} \mathrm{C}$, followed by staining with 5\% Coomassie Brilliant Blue (Sigma, St. Louis, MO).

\section{Propidium iodide (PI) uptake analysis}

A PI uptake analysis was performed, as described in our previous report [33], to detect $\gamma$-IR-induced cell death on $\mathrm{C6L}$ cells. C6L cell samples were prepared as for the invasion analysis; C6L cells were seeded in a $35-\mathrm{mm}$ cell culture dish and cultured overnight. The seeded cells were irradiated with 1, 3, 5, 7 Gy of $\gamma$-IR, and then incubated for an additional 18 hours. The cells were harvested and stained with PI solution $(5 \mathrm{mg} / \mathrm{mL}$, Sigma, St. Louis, MO, USA), and then analyzed with a BD FACSCalibur flow cytometer (BD Biosciences, San Jose, CA, USA).

\section{Formation of Xenografts and Irradiation with $\gamma$-ionizing radiation}

C6L cells $\left(5 \times 10^{5}\right)$ were injected s.c. into the right hind legs of 6 week-old BALB/cAnNCrj-nu/nu mice (Charles River Japan, Inc., Tokyo) to construct xenografts, as described in a previous report by Park et al. [34]. Xenografts reaching more than $100 \mathrm{~mm}^{3}$ were treated with $\gamma$-IR at 10 Gy per day for 5 days, but not the mock control group. Mice were anesthetized i.p. with Zoletil 50 $0^{\mathrm{mm}}$ (VIRBAC Laboratories, Carros) and fixed on an acryl plate. Xenografts were locally irradiated with a ${ }^{60} \mathrm{Co} \gamma$-IR source (Theratrom 780; AECL, Ltd., Mississauga, ON), while other body parts were protected with lead blocks. Tumor sizes and survival curves of the control or radiation-treated groups were assessed for 62 days. Tumor sizes were established with a caliper rule (Mitutoyo Co. Japan), and the volume of each xenograft calculated as follows: [(short axis ${ }^{2} \times$ long axis)/2].

\section{Bioluminescence imaging acquisition}

Bioluminescence imaging was performed with a CCD camera mounted in a light-tight specimen chamber (IVIS200, Xenogen, CA). For in vivo imaging, mice were administered $100 \mu \mathrm{L}$ of $2.5 \mathrm{mg} / 100 \mu \mathrm{L}$ D-luciferin potassium salt i.p. and anesthetized with $2 \%$ isoflurane. Imaging and quantification of signals were controlled with the acquisition and analysis software Living Image V. 2.50 (Xenogen), as described previously by Jang et al. [35].

\section{Histological analysis and Immunohistochemistry}

To perform histological analysis, metastatic lesions were fixed with formaldehyde and embedded in a paraffin block. Sliced tissues were stained Hematoxylin \& Eosin solution, and histological analysis performed under a microscope. Immunohistochemistry for the detection of EMT markers in lesions was also performed with the CAP-PLUS $^{\text {тм }}$ Broad Spectrum kit (Zymed Laboratories Inc. South San Francisco, CA), as described in the manufacturer's protocol. Tissue sections of the lesions were deparaffinized with xylene, rehydrated, and incubated in citric acid buffer $(0.01 \mathrm{M}, \mathrm{pH} 6.0)$ for $20 \mathrm{~min}$ at $100^{\circ} \mathrm{C}$. Incubated sections were cooled slowly at room temperature for $20 \mathrm{~min}$, and endogenous peroxidase activity blocked by treatment with $\mathrm{H}_{2} \mathrm{O}_{2}$ for $15 \mathrm{~min}$. Sections were incubated with primary antibodies (antiVimentin and anti-E-cadherin) overnight at $4^{\circ} \mathrm{C}$ and washed with $0.05 \%$ Tween 20-containing PBS buffer three times. Secondary antibody, streptavidin, and DAB were sequentially added to the sections for visualization of vimentin and E-cadherin, followed by treatment with autohematoxylin for counterstaining of nuclei.

\section{Statistical analysis}

All experiments were repeated at least three times, but Figures $1 \mathrm{~B}$ and $1 \mathrm{E}$ were performed at duplicate. Data 


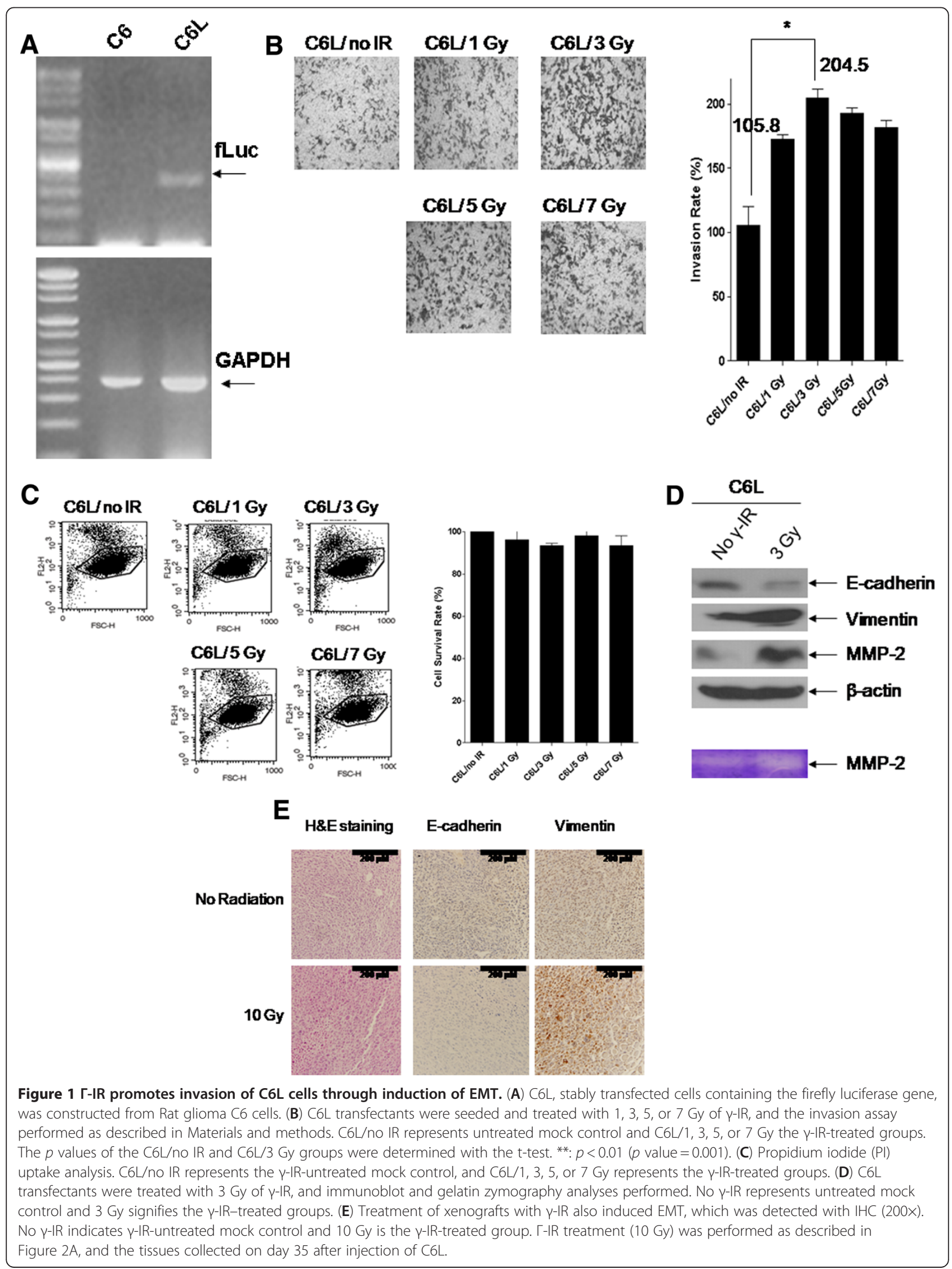


were calculated with GraphPad Prism (GraphPad Software INC. CA), and differences between the experimental groups determined using a $t$-test and one way-ANOVA. Error bars indicate standard deviations (SD), and $p$-values were calculated.

\section{Results \\ $\Gamma$-IR promotes invasiveness via induction of EMT in vitro and in vivo}

In this study, we investigated the possibility that $\gamma$-IR promotes metastasis in an in vivo murine model system. We constructed a firefly luciferase (fLuc)-expressing C6L transfectant cell line derived from the rat glioma cell line, C6. Construction of the C6L cell line was confirmed with PCR analysis using firefly luciferase primer and GAPDH (Figure 1A). We observed expression of exogenous $f L u c$ gene in the C6L cell line, but no detectable $f L u c$ gene in C6 cells. This result implies that expression of fluc is a prominent selective marker in the mouse system in vivo in addition to bioluminescent assay in vitro. Enhanced invasion of C6L cells following $\gamma$-IR treatment was detected in a dose-dependent manner based on quantitative analysis using matrigel-coated transwells (Figure 1B). Treatment with 3 Gy of $\gamma$-IR induced the maximum increase in C6L cell invasion by more than two-fold. But treatments of $\gamma$-IR in a dosedependent manner did not affect C6L cell survival (Figure 1C). To further elucidate the intracellular signaling machinery underlying the $\gamma$-IR-induced increase in the invasive ability of C6L, we performed immunoblot analysis with the EMT markers, E-cadherin, vimentin, and MMP-2 (Figure 1C upper panel). We detected decreased E-cadherin expression and increased vimentin/MMP-2 expression, concurrent with the typical induction patterns of EMT markers. Increased MMP-2 activity was also observed with the gelatin zymography assay (Figure $1 \mathrm{C}$, lower panel). In another preliminary experiment, we treated xenografts with 10 Gy of $\gamma$-IR, and isolated the tissue for IHC analyses with EMT markers (Figure 1D). IHC analysis with anti-E-cadherin or anti-vimentin antibodies revealed a decrease in Ecadherin and increase in vimentin expression, respectively. Based on these findings, we propose that induction of EMT might be the underlying cause of $\gamma$-IR-induced metastasis.

T-IR caused regression of tumors and prolonged survival but did not block death of the in vivo model perfectly

To further establish whether $\gamma$-IR induces metastasis of cancer in vivo, we constructed xenografts with $5 \times 10^{5}$ C6L cells irradiated with $\gamma$-IR, as described in Materials and methods. The experimental schedule in which bioluminescence images were detected every 7 days from day 35 is presented in Figure 2A. Preliminary studies on xenograft size and survival in mice subjected to $\gamma$-IR treatment were performed (Figures $1 \mathrm{~A}$ and $2 \mathrm{~B}$ ). We calculated the time-periods needed for xenograft sizes of each group to reach $2500 \mathrm{~mm}^{3}$ (Figure 2B). Notably, the control group reached this size in 4 days and the $\gamma$-IR treatment group in 45.7 days, revealing a 41.3-day growth delay in terms of xenograft size (Figure 2B). With regard to survival rates, $50 \%$ of $\gamma$-IR-treated mice survived until day 61 , while control mice did not survive for more than 44 days (Figure 2C). Our results indicate that a total of 50 Gy of $\gamma$-IR effectively reduces xenograft size and extends survival in mice, but does not eliminate the tumor completely. Failure of complete tumor eradication by $\gamma$-IR suggests the possibility of tumor recurrence. As shown in Figures $2 \mathrm{~B}$ and $2 \mathrm{C}$, rapid tumor growth and death of mice in the $\gamma$-IR treatment group were detected from day 40. Death of mice displaying smaller tumor sizes in the $\gamma$-IR treatment group, compared to those in the control group indicates the occurrence of metastasis at a secondary site.

\section{Metastases following $\mathrm{Y}$-IR treatment were detected in the murine in vivo model}

Metastasis from the primary site to internal organs following $\gamma$-IR treatment was detected with bioluminescence imaging in vivo and ex vivo using fluc activity of C6L cells in xenografts. We constructed xenografts of 40 mice in total and treated them with $\gamma$-IR, as shown in Figure 2A. Bioluminescence images were detected, as described in Materials and methods. Bioluminescence signals in the body trunks of mice, except the xenograft sites, were observed in $9(22.5 \%)$ among the 40 mice. Specifically, 5 mice displaying bioluminescence presented signals in the chest region and 4 in the abdomen region (Figures $3 \mathrm{~A}$ and $3 \mathrm{~B}$ ). To ascertain the occurrence of metastasis and the exact site, mice were sacrificed, and bioluminescence imaging (ex vivo bioluminescence image) was performed again with the abdomen open to obtain the precise location of tumor growth in organs including brains. Ex vivo bioluminescence images were detected in 3 among 5 mice displaying signals in the chest region (Figure 3A). Lung metastases were observed in ex vivo bioluminescence images, but brain metastases were not. Relationship analysis of fLuc activity with tumor volume in vivo indicated a time-dependent increase in signal intensity (Figures $3 \mathrm{C}$ and $3 \mathrm{D}$ ).

\section{Metastases in the animal model may be accompanied by EMT induction}

Although ex vivo bioluminescence image analysis failed to completely reveal bioluminescence signals in mice subjected to whole autopsy, several lesions estimated as neoplasms in the lung and intestine were observed with visual assessment (Figure 4A). Lesions were further 


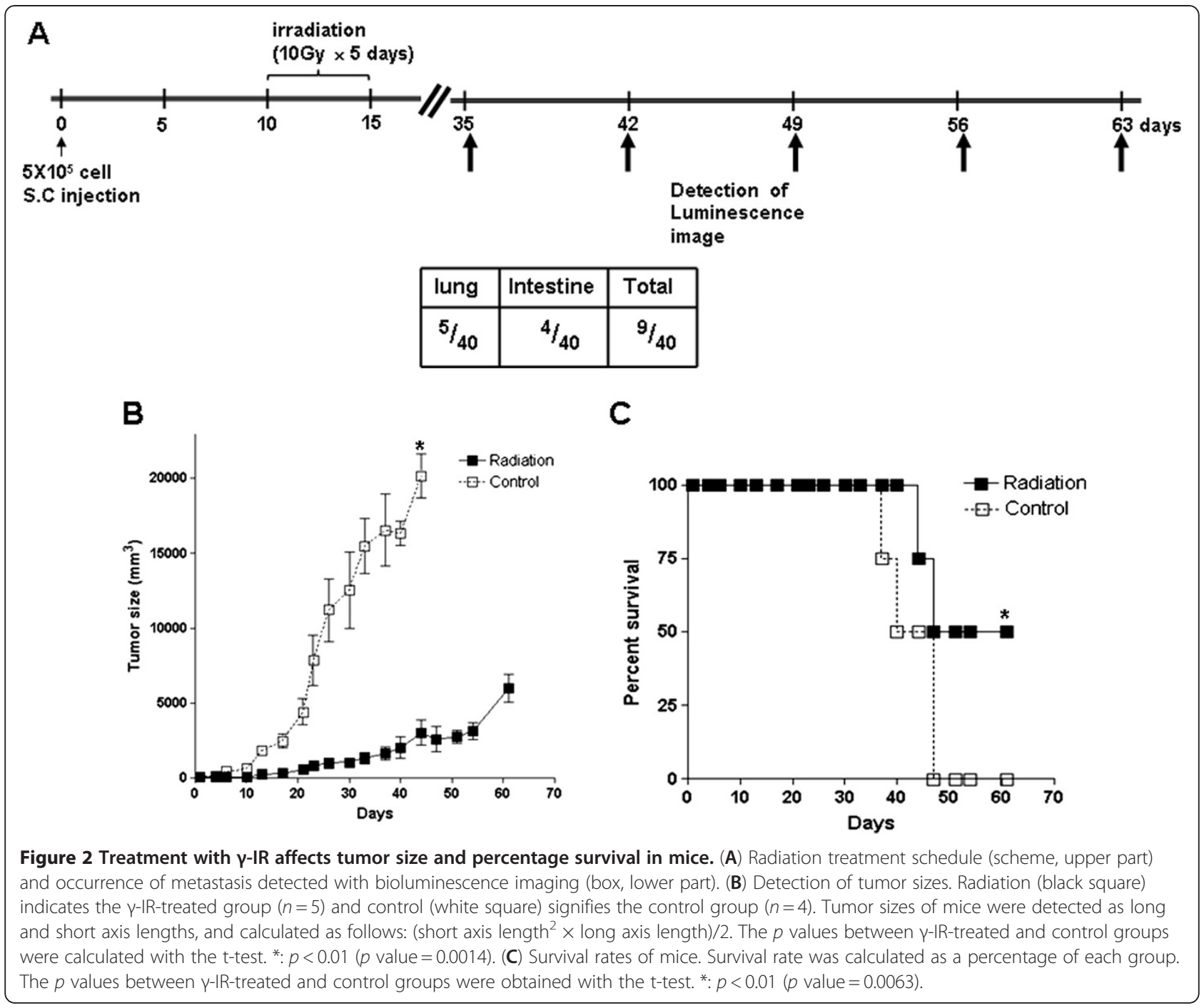

analyzed by PCR with $f L u c$ or GAPDH primers (Figure 4B) and histological experiments (Figure 4C). As shown in Figure 4B, each lesion expressed the fluc gene, indicative of its origin from C6L xenografts as a primary cancer. $\mathrm{H} \& \mathrm{E}$ staining in histological analysis revealed the formation of solid tumors in normal lung and intestine tissues (Figure 4C). These results suggest that $\gamma$-IR promotes metastasis in vivo as well as in vitro, and induction of cancer spread by irradiation is accomplished randomly. To identify changes in intracellular signaling or physiological phenomena occurring in $\gamma$-IR-induced metastasis, we assessed the expression of ECM markers in histological tissue samples (Figure 4D). IHC analysis with E-cadherin or vimentin disclosed different expression patterns in cancer and normal sites. Specifically, Ecadherin was expressed at the normal site in each tissue (lung and intestine), while vimentin was expressed at the cancer site in each tissue, especially in the intestine, where expression was detected in the lesion center.

\section{Discussion}

Although $\gamma$-IR is one of most useful known tools for cancer treatment to date, many investigators have reported metastasis from primary cancer following irradiation. As reported previously in a review by C.F. von Essen [36], various researchers have described two distinct cases of metastasis induced by $\gamma$-IR, whereby (1) increased metastasis is triggered following local irradiation against primary cancer, and (2) localization of metastases is increased in $\gamma$-IR-pretreated normal tissues. In the current study, we have demonstrated that $\gamma$-IR treatment of primary cancer xenografts of the C6L cell line induces distant metastasis in vivo and enhances the invasiveness of C6L in vitro via induction of EMT. We generated a C6L cell line expressing fLuc from parental C6 and further examined whether local $\gamma$-IR treatment of xenografts constructed from our cell line promotes distant metastasis. In our previous report [35], we used C6 cells to construct C6TL cells containing the herpes 




simplex virus type-1 thymidine kinase (HSV1-tk) and firefly luciferase (fLuc) genes for gene therapy against glioma and found that the genetically modified C6 cell line is a very effective monitoring system for Bioluminescence imaging or microPET due to their high fLuc activity and iodine-125 iodovinyldeoxyuridine uptake. We used nude mice, because the entire body of hairless nude mice provided a chance to observe the Bioluminescence signal more efficiently in the body trunk. C6L was initially generated from the $\mathrm{C} 6$ rat glioma cell line derived from C6 glioblastoma tumors in Sprague-Dawley and Wistar rats, which display significant invasion and a diffuse infiltrating border in which each $\mathrm{C} 6$ cell moves to normal brain tissue beside the tumor area [37]. Thus, C6 

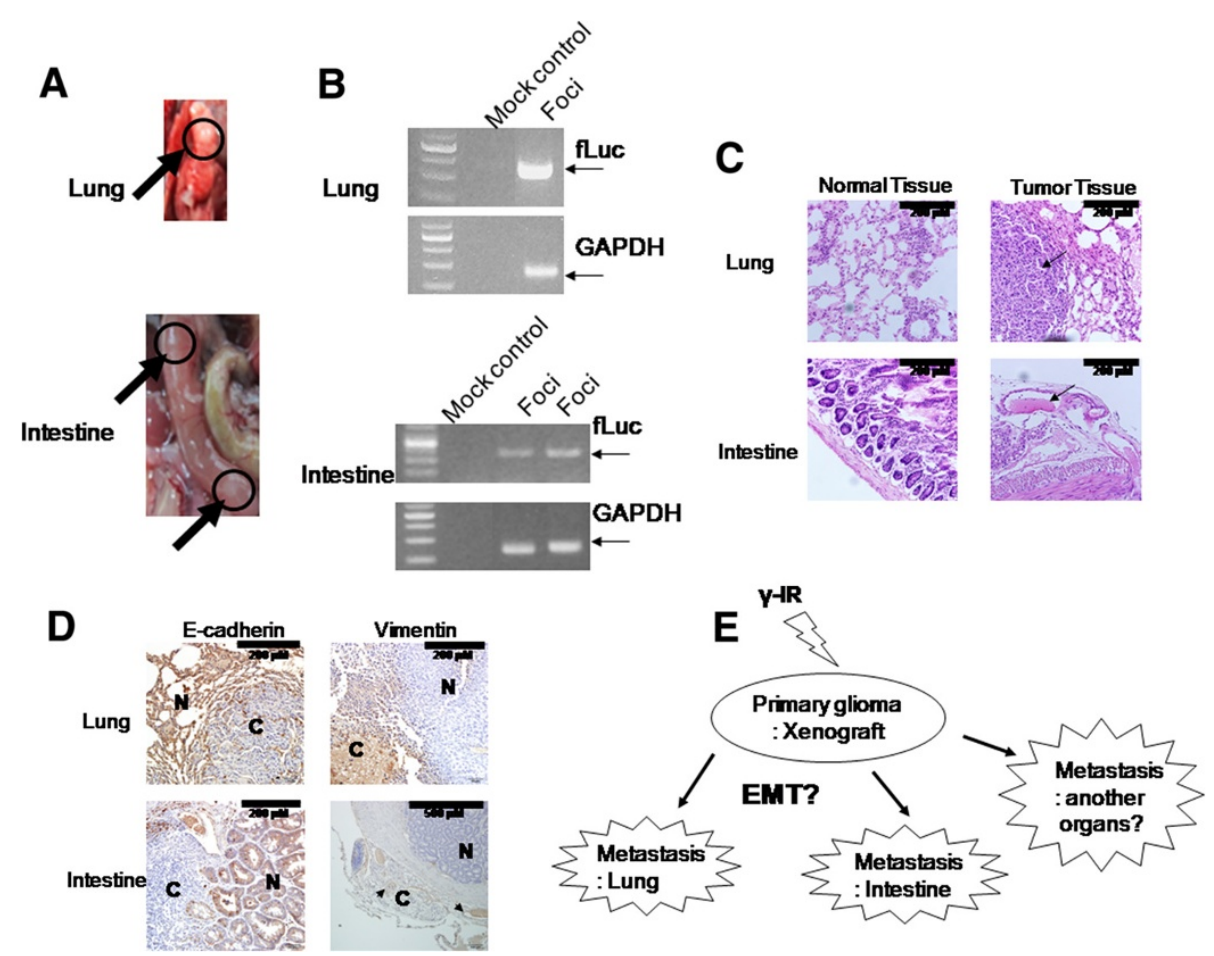

Figure 4 Histological or genetic analysis of metastatic lesions. (A) Mice displaying bioluminescence signals upon imaging were scarified and dissected. Lesions in the lung and intestine were observed (black arrows and circles). (B) The fluc gene in lesions was detected with PCR. (C) Histological analysis revealed that each lesion displays characteristics typical of cancer tissue (200X). (D) IHC analysis. E-cadherin was expressed in normal tissue, while vimentin was expressed in cancer tissue ( $\mathrm{N}$ : normal tissue, C: cancer tissue) [200x except to vimentin staining of intestine $(100 \times)]$. (E) Scheme of $\mathrm{Y}-\mathrm{IR}$ - induced metastasis.

could be useful to investigate invasion of glioma as a glioblastoma model system. Park et al. [28] demonstrated that $\gamma$-IR treatment increases invasion through activity or expression of MMP-2 via activation of Src/ epidermal growth factor receptor-mediated p38/Akt and PI3-Kinase/Akt signaling in various non-functional PTEN-bearing glioma cells, including C6. We additionally showed that irradiation of the C6L cell line via induction of EMT (Figure 1C). Our results are consistent with previous reports showing that $\gamma$-IR-treated nonsmall cell lung cancer (NSCLC) cell lines display increased invasion via EMT induction, characterized by activation of MMP protein [22,38]. Moreover, we demonstrated previously that $\gamma$-IR promotes the level of $\mathrm{Bcl}-\mathrm{xL}$, a pro-survival protein, in a manner dependent on signal transducer and activator of transcription 3 (STAT3) phosphorylation [22]. Treatment with $\gamma$-IR also enhanced invasion of hepatocellular carcinoma cell (HCC) cell lines via the PI3-Kinase/Akt/NF-кB/MMP-9 pathway [27].

Next, we performed experiments to establish whether the increased invasiveness of C6L by $\gamma$-IR promotes metastasis in vivo. The schedule for $\gamma$-IR treatment of xenografts was followed as described by Camphausen et al. [39], who used Lewis lung carcinoma (LLC-LM) cells to confirm that $\gamma$-IR promotes metastasis in an animal model and suggested that increased levels of MMP-2 may be related to enhancement of metastases. Survival and tumor sizes in mice showed that local $\gamma$-IR treatment decreases tumor size and elongates survival of mice but do not block metastasis completely. C.F. von Essen also suggested three possible mechanisms underlying the promotion of metastases by local irradiation, specifically, (1) direct alterations in $\gamma$-IR-treated cancer cells (2) promotion of entry of cancer cells into the circulation, and (3) extension of time needed for entry of cancer cells into the circulation. Data from the present study indicate that $\gamma$-IR treatment can elongate survival times in mice, leading to entry of cancer cells into the circulation. Thus, the third hypothesis of C.F. von Essen is consistent with our results. We need to test the other hypotheses in future studies to clarify the molecular mechanism underlying $\gamma$-IR-induced metastasis.

To detect the occurrence of metastasis in internal organs of the in vivo murine system, we used the bioluminescence imaging system containing charged coupled device (CDD) detectors. As this system provides noninvasive in vivo optical images, we traced the occurrence of metastasis during several weeks. Molecular imaging techniques are based on nuclear medicine that is 
concentrated to manage and diagnose diseases through injection of radiolabeled tracers [40]. As recent development of bioluminescence imaging systems results from advances in molecular biology and biochemistry, the technique consists of optical imaging systems with fluorescence imaging whereby molecular probes are required to detect specific signals in living subjects. Various biocompatible molecular probes, including chemicals and reporter genes, have been used for optical imaging. In particular, several intracellular reporter genes have been developed and applied, including GFP, thymidine kinase, cytosine deaminase, tyrosinase, and luciferase [41]. Luciferases constitute a family of enzymes originating from diverse fireflies or beetles that emit their own specific wavelength of light using specific substrates and biochemical pathways [42]. As shown in Figures $3 \mathrm{~A}$ and $3 \mathrm{~B}$, we detected bioluminescence signals in the chest or abdomen of living mice, which were regarded as metastatic lesions. Some mice showed increased bioluminescence signals in a time-dependent manner in a relationship analysis of fLuc activity. Ex vivo image detection of bioluminescence signals at the final step was also performed to confirm the signals in body trunks of mice. Our results provide evidence that optical bioluminescence signal detection is a useful non-invasive diagnostic tool for metastasis.

We observed several metastatic lesions in the lung or intestine after autopsy. Interestingly, metastatic lesions were not detected in several internal organs simultaneously in each mouse, but the possibility that undetected metastatic lesions in other visceral organs were discovered remained, because we did not perform a complete dissection of the entire mouse. Metastatic lesions of the lung were identified with hardened tissues, and those of the intestine formed white, small-sized cysts. RT-PCR results obtained using RNA from metastatic lesion tissues indicated that these lesions contain the fLuc gene and therefore originate from C6L cells in the primary cancer located a distance away. Histological analysis with $\mathrm{H}$ \& E staining revealed that the metastatic lesions are typical cancerous lesions with poorly differentiated morphology, compared with those of healthy lung and intestine tissue. IHC examination with anti-E-cadherin and anti-vimentin antibodies further showed that cancer sites in metastatic lesions contain low E-cadherin/high vimentin levels, while conversely, normal tissue sites present with high E-cadherin/low vimentin expression levels. These results were inconsistent with the typical EMT theory hypothesizing that increases in cancer cell migration/invasion via induction of EMT promote cancer cell movement to a new site for metastasis formation and that mesenchymal-to-epithelial transition (MET) is required for settlement of cancer cells $[19,43]$. However, several clinical reports indicate that loss of E-cadherin in gastric/colorectal cancer and increased vimentin expression in NSCLC/gastric cancer are markers for cancer progression, metastasis and poorer prognosis [44-47]. Therefore, we could postulate that MET might be a transient event that is induced to promote formation of the metastasis site, followed by progression of metastatic lesions.

However, there are other possibilities that EMT might not be the main or only cause of radiation-induced metastasis in our system, because Tarin et al. reported no confirmative evidence that EMT can be induced in vivo [48]. Instead, fused hybrids of macrophages and non-metastatic cancer stem cells can metastasize in vivo [49-51]. Moreover, Mor-Vaknin et al. reported that activated macrophages induce secretion of vimentin and up-regulate MMP proteins [52]. Because radiation might be a cause of macrophage-cancer cell fusion [53,54], fusion hybrids of macrophages and cancer cells in our system might be discovered. According to Kliopp et al. irradiated tumors recruit circulating mesenchymal stem cells into their microenvironment by increasing expression of several cytokines that might activate macrophages [55]. These previous reports suggest that further studies on the relationship between the immune system and radiationrelated metastasis are needed to validate our animal model. EMT expression markers at distal metastatic lesions are also required to investigate the relationship with the immune system.

Together, our results suggest that radiotherapy alone could promote metastasis as an undesired effect and $\gamma$ IR-induced metastasis in vivo is evoked via the EMT pathway. Data obtained with our in vivo animal model may be employed for the development of drugs blocking radiation-induced metastasis. In previous reports, administration of recombinant angiostatin after cancer cell injection in vivo blocked the formation of metastases by $\gamma$-IR [39], and neutralization of TGF- $\beta$ with its specific antibody inhibited $\gamma$-IR-induced metastasis [56]. Although molecular targets for blockage of $\gamma$-IR-induced metastases in our system are yet to be identified, the EMT pathway may be a significant candidate for drug development. In fact, upstream molecules of the EMT pathway, including TGF- $\beta$ receptor, integrin, Wnt, or Notch signaling, represent targets for anti-cancer drug development [20,57]. Development of novel drugs to block $\gamma$-IR-induced metastasis may maximize the beneficial effects of radiotherapy and improve treatment outcomes.

\section{Conclusion}

This study is focused on the construction of an animal model for the development of inhibitor to block the metastatic process which occurs during radiotherapy. I-IR treatment did not block the occurrence of 
metastases in mice containing xenografts of C6L cells. Induction of EMT markers was detected in $\gamma$-IR - treated cells, xenografts, and metastatic lesions in mice. Therefore, our results also suggested EMT might be one of the major therapeutic targets to block metastasis

\section{Abbreviations}

EMT: Epithelial-mesenchymal transition; ECM: Extracellular matrix; IR: Ionizing radiation; PI3Kinase: Phosphatidylinositol 3-kinase; ERK: Extracellular signalingreceptor kinase; BDNF: Brain-derived neurotrophic factor; HGF: Hepatocyte growth factor; MMP: Matrix metalloproteinase; UV: Ultraviolet light; fLuc: Firefly luciferase; PI: Propidium iodide; SDS: Sodium dodecyl sulfate; PAGE: Polyacrylamide gel electrophoresis; GAPDH: Glyceraldehyde-3phosphate dehydrogenase; SD: Standard deviations; STAT3: Signal transducer and activator of transcription 3; HCC: Hepatocellular carcinoma cell; LLCLM: Lewis lung carcinoma; CDD: Charged coupled device; MET: Mesenchymal-to-epithelial transition.

\section{Competing interests}

The authors declare that they have no competing interests.

\section{Authors' contribution}

JKP, SJJ and SWK performed animal experiments, immunoblot assay, PCR, statistical analysis. SP, SGH and WJK carried out animal tissue collection, immunohistochemistry and interpretation of the immunohistochemistry data. JHK designed experiments for bioluminescence imaging and HDU coordinated whole experiments. JKP, JHK and HDU prepared manuscript. All authors read and approved final manuscript.

\section{Acknowledgements}

This work was supported by the Nuclear Research \& Development Program (2012M2A2A7010459) of the National Research Foundation of Korea (NRF) grant funded by the Korean government (MEST) and in part by the Basic Science Research Program through the NRF (2012-0000482).

\section{Author details}

${ }^{1}$ Division of Radiation Cancer Biology, Korea Institute of Radiological and Medical Sciences, 215-4, Gongneung-Dong, Nowon-Gu, Seoul 139-706, Republic of Korea. ${ }^{2}$ Molecular Imaging Research Center, Korea Institute of Radiological and Medical Sciences, 215-4, Gongneung-Dong, Nowon-Gu, Seoul 139-706, Republic of Korea. ${ }^{3}$ Laboratory of Radiation Pathology, Korea Institute of Radiological and Medical Sciences, 215-4, Gongneung-Dong, Nowon-Gu, Seoul 139-706, Republic of Korea. ${ }^{4}$ Department of Urology, College of Medicine, Chungbuk National University, Chungbuk, Korea.

Received: 3 April 2012 Accepted: 4 September 2012

Published: 11 September 2012

\section{References}

1. Gupta GP, Massagué J: Cancer metastasis: building a framework. Cell 2006, 127(4):679-695.

2. Weber GF: Molecular mechanisms of metastasis. Cancer Lett 2008, 270(2):181-190.

3. Friedl $P$, Wolf $K$ : Tumour-cell invasion and migration: diversity and escape mechanisms. Nat Rev Cancer 2003, 3(5):362-374.

4. Pavelic SK, Sedic M, Bosnjak H, Spaventi S, Pavelic K: Metastasis: new perspectives on an old problem. Mol Cancer 2011, 10:22.

5. Box C, Rogers SJ, Mendiola M, Eccles SA: Tumour-microenvironmental interactions: paths to progression and targets for treatment. Semin Cancer Biol 2010, 20(3):128-138.

6. Pani G, Galeotti T, Chiarugi P: Metastasis: cancer cell's escape from oxidative stress. Cancer Metastasis Rev 2010, 29(2):351-378.

7. Gatenby RA, Gillies RJ: Why do cancers have high aerobic glycolysis? Nat Rev Cancer 2004, 4(11):891-899.

8. Lu X, Kang Y: Hypoxia and hypoxia-inducible factors: master regulators of metastasis. Clin Cancer Res 2010, 16(24):5928-5935.

9. Xu RH, Pelicano H, Zhou Y, Carew JS, Feng L, Bhalla KN, Keating MJ, Huang P: Inhibition of glycolysis in cancer cells: a novel strategy to overcome drug resistance associated with mitochondrial respiratory defect and hypoxia. Cancer Res 2005, 65(2):613-621.
10. Sierra A: Metastases and their microenvironments: linking pathogenesis and therapy. Drug Resist Updat 2005, 8(4):247-57.

11. Frisch SM, Ruoslahti E: Integrins and anoikis. Curr Opin Cell Biol 1997, 9(5):701-706.

12. Glinskii AB, Smith BA, Jiang P, Li XM, Yang M, Hoffman RM, Glinsky GV: Viable circulating metastatic cells produced in orthotopic but not ectopic prostate cancer models. Cancer Res 2003, 63(14):4239-4243

13. Geiger TR, Peeper DS: The neurotrophic receptor TrkB in anoikis resistance and metastasis: a perspective. Cancer Res 2005, 65(16):7033-7036.

14. Rennebeck G, Martelli M, Kyprianou N: Anoikis and survival connections in the tumor microenvironment: is there a role in prostate cancer metastasis? Cancer Res 2005, 65(24):11230-11235.

15. Park JK, Park SH, So K, Bae IH, Yoo YD, Um HD: ICAM-3 enhances the migratory and invasive potential of human non-small cell lung cancer cells by inducing MMP-2 and MMP-9 via Akt and CREB. Int J Oncol 2010, 36(1):181-192

16. Bae IH, Park MJ, Yoon SH, Kang SW, Lee SS, Choi KM, Um HD: Bcl-w promotes gastric cancer cell invasion by inducing matrix metalloproteinase-2 expression via phosphoinositide 3-kinase, Akt, and Sp1. Cancer Res 2006, 66(10):4991-4995.

17. Chung T-W, Lee $Y-C$, Kim C-H: Hepatitis B viral HBx induces matrix metalloproteinase-9 gene expression through activation of ERK and PI3 K/AKT pathways: Involvement of invasive potential. FASEB J 2004, 18:1123-1125.

18. Lee JM, Dedhar S, Kalluri R, Thompson EW: The epithelial-mesenchymal transition: new insights in signaling, development, and disease. J Cell Biol 2006, 172(7):973-981.

19. Yang J, Weinberg RA: Epithelial-Mesenchymal Transition: at the Crossroads of Development and Tumor Metastasis. Dev Cell 2008, 14:818-829.

20. Thiery JP, Acloque H, Huang RY, Nieto MA: Epithelial-mesenchymal transitions in development and disease. Cell 2009, 139(5):871-890.

21. Peinado $H$, Olmeda D, Cano A: Snail, Zeb and bHLH factors in tumour progression: an alliance against the epithelial phenotype? Nat Rev Cancer 2007, 7(6):415-428

22. Ho JN, Kang GY, Lee SS, Kim J, Bae IH, Hwang SG, Um HD: Bcl-XL and STAT3 mediate malignant actions of gamma-irradiation in lung cancer cells. Cancer Sci 2010, 101(6):1417-1423.

23. Shah AN, Summy JM, Zhang J, Park SI, Parikh NU, Gallick GE: Development and characterization of gemcitabine-resistant pancreatic tumor cells. Ann Surg Oncol 2007, 14(12):3629-3637.

24. Hiscox S, Jiang WG, Obermeier K, Taylor K, Morgan L, Burmi R, Barrow D, Nicholson Rl: Tamoxifen resistance in MCF7 cells promotes EMT-like behaviour and involves modulation of beta-catenin phosphorylation. Int J Cancer 2006, 118(2):290-301.

25. Hiscox S, Morgan L, Barrow D, Dutkowskil C, Wakeling A, Nicholson Rl: Tamoxifen resistance in breast cancer cells is accompanied by an enhanced motile and invasive phenotype: inhibition by gefitinib ('Iressa', ZD1839). Clin Exp Metastasis 2004, 21(3):201-212.

26. Iwatsuki M, Mimori K, Yokobori T, Ishi H, Beppu T, Nakamori S, Baba H, Mori M: Epithelial-mesenchymal transition in cancer development and its clinical significance. Cancer Sci 2010, 101(2):293-299.

27. Cheng JC, Chou CH, Kuo ML, Hsieh CY: Radiation-enhanced hepatocellular carcinoma cell invasion with MMP-9 expression through PI3K/Akt/NFkappaB signal transduction pathway. Oncogene 2006, 25(53):7009-7018.

28. Park CM, Park MJ, Kwak HJ, Lee HC, Kim MS, Lee SH, Park IC, Rhee CH, Hong SI: lonizing radiation enhances matrix metalloproteinase- 2 secretion and invasion of glioma cells through Src/epidermal growth factor receptormediated p38/Akt and phosphatidylinositol 3-kinase/Akt signaling pathways. Cancer Res 2006, 66(17):8511-8519.

29. Ahmed KM, Li JJ: NF-kappa B-mediated adaptive resistance to ionizing radiation. Free Radic Biol Med 2008, 44(1):1-13.

30. Piva R, Belardo G, Santoro MG: NF-kappaB: a stress-regulated switch for cell survival. Antioxid Redox Signal 2006, 8(3-4):478-486.

31. Huang WC, Hung MC: Induction of Akt activity by chemotherapy confers acquired resistance. J Formos Med Assoc 2009, 108(3):180-194.

32. Kraus AC, Ferber I, Bachmann SO, Specht H, Wimmel A, Gross MW, Schlegel J, Suske G, Schuermann M: In vitro chemo- and radio-resistance in small cell lung cancer correlates with cell adhesion and constitutive activation of AKT and MAP kinase pathways. Oncogene 2002, 21(57):8683-8695. 
33. Kim EM, Yang HS, Kang SW, Ho JN, Lee SB, Um HD: Amplification of the gamma-irradiation-induced cell death pathway by reactive oxygen species in human U937 cells. Cell Signal 2008, 20(5):916-924

34. Park JK, Chung YM, Kim BG, Yoo YA, Yang BS, Kim JS, Yoo YD: N'-(phenylpyridin-2-yl-methylene)-hydrazine carbodithioic acid methyl ester enhances radiation-induced cell death by targeting $\mathrm{Bcl}-2$ against human lung carcinoma cells. Mol Cancer Ther 2004, 3(4):403-407.

35. Jang SJ, Kang JH, Kim Kl, Lee TS, Lee YJ, Lee KC, Woo KS, Chung WS, Kwon HC, Ryu CJ, Choi TH, Choi CW, Lim SM, Cheon GJ: Application of bioluminescence imaging to therapeutic intervention of herpes simplex virus type I - Thymidine kinase/ganciclovir in glioma. Cancer Letts 2010, 297(1):84-90.

36. von Essen CF: Radiation enhancement of metastasis: a review. Clin Exp Metastasis 1991, 9(2):77-104.

37. Grobben B, De Deyn PP, Slegers H: Rat C6 glioma as experimental model system for the study of glioblastoma growth and invasion. Cell Tissue Res 2002, 310(3):257-270.

38. Jung JW, Hwang SY, Hwang JS, Oh ES, Park S, Han IO: lonizing radiation induces changes associated with epithelial-mesenchymal transdifferentiation and increased cell motility of A549 lung epithelial cells. Eur J Cancer 2007, 43(7):1214-1224.

39. Camphausen K, Moses MA, Beecken WD, Khan MK, Folkman J, O'Reilly MS: Radiation therapy to a primary tumor accelerates metastatic growth in mice. Cancer Res 2001, 61(5):2207-2211.

40. Massoud TF, Gambhir SS: Molecular imaging in living subjects: seeing fundamental biological processes in a new light. Genes Dev 2003, 17(5):545-580

41. Contag CH, Jenkins D, Contag PR, Negrin RS: Use of Reporter Genes for Optical Measurements of Neoplastic Disease In vivo. Neoplasia 2000 2(1-2):41-52.

42. Viviani VR: The origin, diversity, and structure function relationships of insect luciferases. Cell Mol Life Sci 2002, 59(11):1833-1850.

43. Thiery JP: Epithelial-mesenchymal transitions in tumour progression. Nat Rev Cancer 2002, 2(6):442-454.

44. Chan AO, Chu KM, Lam SK, Wong BC, Kwok KF, Law S, Ko S, Hui WM, Yueng $\mathrm{YH}$, Wong J: Soluble E-cadherin is an independent pretherapeutic factor for long-term survival in gastric cancer. J Clin Oncol 2003, 21(12):2288-2293.

45. Dorudi S, Hanby AM, Poulsom R, Northover J, Hart IR: Level of expression of E-cadherin mRNA in colorectal cancer correlates with clinical outcome. Br J Cancer 1995, 71(3):614-616.

46. Al-Saad S, Al-Shibli K, Donnem T, Persson M, Bremnes RM, Busund LT: The prognostic impact of NF-kappaB p105, vimentin, E-cadherin and Par6 expression in epithelial and stromal compartment in non-small-cell lung cancer. Br J Cancer 2008, 99(9):1476-1483.

47. Utsunomiya T, Yao T, Masuda K, Tsuneyoshi M: Vimentin-positive adenocarcinomas of the stomach: co-expression of vimentin and cytokeratin. Histopathology 1996, 29(6):507-516.

48. Tarin D, Thompson EW, Newgreen DF: The fallacy of epithelial mesenchymal transition in neoplasia. Cancer Res 2005, 65(14):5996-6000.

49. Pawelek JM, Chakraborty AK: The cancer cell-leukocyte fusion theory of metastasis. Adv Cancer Res 2008, 101:397-444.

50. Huysentruyt LC, Seyfried TN: Perspectives on the mesenchymal origin of metastatic cancer. Cancer Metastasis Rev 2010, 29(4):695-707.

51. Powell $A E$, Anderson EC, Davies PS, Silk AD, Pelz C, Impey S, Wong MH: Fusion between Intestinal epithelial cells and macrophages in a cancer context results in nuclear reprogramming. Cancer Res 2011, 71(4):1497-1505

52. Mor-Vaknin N, Punturieri A, Sitwala K, Markovitz DM: Vimentin is secreted by activated macrophages. Nat Cell Biol 2003, 5(1):59-63.

53. Adès $L$, Guardiola $P$, Sociè $G$ : Second malignancies after allogeneic hematopoietic stem cell transplantation: new insight and current problems. Blood Rev 2002, 16(2):135-146.

54. Shabo I, Olsson H, Sun XF, Svanvik J: Expression of the macrophage antigen CD163 in rectal cancer cells is associated with early local recurrence and reduced survival time. Int J Cancer 2009, 125(8):1826-1831.

55. Klopp AH, Spaeth EL, Dembinski JL, Woodward WA, Munshi A, Meyn RE, Cox JD, Andreeff M, Marini FC: Tumor irradiation increases the recruitment of circulating mesenchymal stem cells into the tumor microenvironment. Cancer Res 2007, 67(24):11687-11695.
56. Biswas S, Guix M, Rinehart C, Dugger TC, Chytil A, Moses HL, Freeman ML, Arteaga CL: Inhibition of TGF-beta with neutralizing antibodies prevents radiation-induced acceleration of metastatic cancer progression. J Clin Invest 2007, 117(5):1305-1313.

57. Cox D, Brennan M, Moran N: Integrins as therapeutic targets: lessons and opportunities. Nat Rev Drug Discov 2010, 9(10):804-820.

doi:10.1186/1748-717X-7-153

Cite this article as: Park et al:: Establishment of animal model for the analysis of cancer cell metastasis during radiotherapy. Radiation Oncology 2012 7:153.

\section{Submit your next manuscript to BioMed Central and take full advantage of:}

- Convenient online submission

- Thorough peer review

- No space constraints or color figure charges

- Immediate publication on acceptance

- Inclusion in PubMed, CAS, Scopus and Google Scholar

- Research which is freely available for redistribution
C Biomed Central 